\title{
Exchange Bias and Spin-Valve Giant Magnetoresistance in Multilayers with Mn-17 mol\%Ir-2 mol\%Pt Antiferromagnetic Layer
}

\author{
Dong-Min Jeon ${ }^{1, *}$, Yoon-Sik Kim ${ }^{1, *}$, Suk-Min Na ${ }^{1, *}$, Jae-Chul Ro ${ }^{2}$, \\ Dae-Ho Yoon ${ }^{1}$ and Su-Jeong Suh ${ }^{1}$ \\ ${ }^{1}$ Department of Advanced Materials Engineering, Sungkyunkwan University, Suwon 440-746, Korea \\ ${ }^{2} R-D$ center, Samsung electro-mechanics, Korea
}

We fabricated bottom spin valves (SV) films using Mn-17 mol\% Ir-2 mol\%Pt antiferromagnetic material. A bottom SV composing of $\mathrm{Ta} / \mathrm{Ni}-20 \mathrm{~mol} \% \mathrm{Fe}$ seed layer shows an improved exchange field $\left(H_{\mathrm{ex}}\right)$. The high $H_{\mathrm{ex}}$ of about $17.4 \mathrm{kA} / \mathrm{m}$ was obtained in Si(100)/Ta $3 \mathrm{~nm} / \mathrm{NiFe}$ $3 \mathrm{~nm} / \mathrm{Mn}-17 \mathrm{~mol} \% \mathrm{Ir}-2 \mathrm{~mol} \% \mathrm{Pt} 7 \mathrm{~nm} / \mathrm{Co}-10 \mathrm{~mol} \% \mathrm{Fe} 1 \mathrm{~nm} / \mathrm{NiFe} 5 \mathrm{~nm} / \mathrm{Ta}$ exchange biasing layer. The giant magnetoresistance (GMR) and the thermal stability of bottom SVs were evaluated by comparing with a top SV. Bottom SV showed the higher GMR ratio of about $5.2 \%$ than a top SV with same thick ferromagnetic layer. It seems that a large short circuit effect of conductance in a free layer of a bottom spin valve. In order to improve thermal stability of a bottom SV, we inserted the synthetic antiferromagnetically coupled pinned layers (Co-Fe/Ru/Co-Fe) between the Mn-17 mol\%Ir-2 mol\%Pt and Cu layers. Thus, the enhanced thermal stability of $H_{\mathrm{ex}}$ can be obtained in bottom synthetic SVs.

(Received September 21, 2001; Accepted March 20, 2002)

Keywords: manganese-iridium-platinum, exchange bias, giant magnetoresistance, spin valve, synthetic antiferromagnetic coupling

\section{Introduction}

Antiferromagnetic (AFM) materials have been extensively studied because of their key importance in MR heads and spin valve read heads. ${ }^{1,2)}$ We have developed a ternary AFM material of $\mathrm{Mn}-17 \mathrm{~mol} \% \mathrm{Ir}-2 \mathrm{~mol} \% \mathrm{Pt}^{3)}$ which showed the larger exchange bias field $\left(H_{\mathrm{ex}}\right)$, the higher thermal stability and the better chemical resistance than Mn-Ir AFM material. Mn$17 \mathrm{~mol} \% \mathrm{Ir}-2 \mathrm{~mol} \% \mathrm{Pt}$ is a disordered phase (face centered crystal structure), ${ }^{3)}$ which doesn't need any annealing process at a high temperature. This is a prominent candidate material for a high sensitive sensor or a magnetic head. We prepared the bottom spin valve (SV) with $\mathrm{Mn}-17 \mathrm{~mol} \% \mathrm{Ir}-$ 2 mol\%Pt AFM material. The bottom SV of Mn-17 mol\%Ir2 mol\%Pt, Mn-Ir and Mn-Fe, compared with a top SV, generally shows a low $H_{\text {ex }}$ and poor thermal stability. If a bottom $\mathrm{SV}$ have a high $H_{\mathrm{ex}}$ and a good thermal stability, it can be applicable a symmetry or dual type SVs, which show an excellent GMR. A synthetic anftiferromagnet consisting of Co$10 \mathrm{~mol} \% \mathrm{Fe} / \mathrm{Ru} / \mathrm{Co}-10 \mathrm{~mol} \% \mathrm{Fe}$ multiplayer with a strong antiferrocoupling, improve a thermal stability over a large temperature and control a magnetostatic interaction between a pinned layer and a free layer in a sub-micron device. ${ }^{4)}$

In this sturdy, we fabricated bottom SVs with various seed layer thickness and evaluated their magnetic properties and GMR response by comparing with a top SVs. In order to improve the thermal properties, we applied synthetic antiferromagnet to a bottom SV and evaluated the thermal stability of a $H_{\mathrm{ex}}$ and GMR.

\section{Experimental Procedure}

Mn-17 mol\%Ir-2 mol\%Pt exchange biased SVs were deposited on the (100) $\mathrm{Si}$ wafer in a magnetron sputtering system with a base pressure of $4 \times 10^{-5} \mathrm{~Pa}$. The deposition pro-

*Graduate Student, Sungkyunkwan University. cesses were done in Ar pressure of 0.4 Pa. And the deposition rates were in the range of $0.05-0.13 \mathrm{~nm} / \mathrm{s}$. The top and bottom SVs were classified with the stacking sequence of an AFM and a ferromagnetic (FM) layer. For the bottom SV, with the $\mathrm{Mn}-17 \mathrm{~mol} \% \mathrm{Ir}-2 \mathrm{~mol} \% \mathrm{Pt}(10 \mathrm{~nm})$ under the $\mathrm{Co}-10 \mathrm{~mol} \% \mathrm{Fe}$ layer, the seed layers of $\mathrm{Ta} / \mathrm{Ni}-20 \mathrm{~mol} \% \mathrm{Fe}$ were used for an enhanced exchange field. ${ }^{5)}$

The exchange coupling energy $\left(J_{\mathrm{ex}}=\mu_{0} H_{\mathrm{ex}} M_{\mathrm{F}} t_{\mathrm{F}}, M_{\mathrm{F}}\right.$ and $t_{\mathrm{F}}$ are a magnetization and a thickness of ferromagnetic) of the SVs with $3 \mathrm{~nm}$ thick $\mathrm{Co}-10 \mathrm{~mol} \% \mathrm{Fe}$ pinned layer was $0.22 \mathrm{~mJ} / \mathrm{m}^{2}$ for a top type and $0.1 \mathrm{~mJ} / \mathrm{m}^{2}$ for a bottom at a $\mathrm{Co}-10 \mathrm{~mol} \% \mathrm{Fe}$ layer a $3 \mathrm{~nm}$. The synthetic SVs were prepared by deposition synthetic antiferromagnet $(\mathrm{Co}-$ $10 \mathrm{~mol} \% \mathrm{Fe} 3 \mathrm{~nm} / \mathrm{Ru} 0.8 \mathrm{~nm} / \mathrm{Co}-10 \mathrm{~mol} \% \mathrm{Fe} 3 \mathrm{~nm}$ ) between $\mathrm{Mn}-17 \mathrm{~mol} \% \mathrm{Ir}-2 \mathrm{~mol} \% \mathrm{Pt}$ and $\mathrm{Cu}$ layers in top and bottom SVs. Magnetic properties of SVs were measured by using vibrating sample magnetometer. X-ray diffraction measurement were performed to structurally characterize the SVs. The GMR was measured by using a four-point probing tester in an external field. And, the thermal stability of GMR and $H_{\text {ex }}$ was evaluated at various temperatures in air.

\section{Results and Discussion}

Figure 1 shows the variation of a $H_{\mathrm{ex}}$ and a coercivity $\left(H_{\mathrm{c}}\right)$ in bottom $\mathrm{SVs}$ as a function of a $\mathrm{Ni}-20 \mathrm{~mol} \% \mathrm{Fe}$ seed layer thickness. As the thickness of $\mathrm{Ni}-20 \mathrm{~mol} \% \mathrm{Fe}$ seed layer increase the $H_{\mathrm{ex}}$ and $H_{\mathrm{c}}$ increase gradually. The $H_{\mathrm{ex}}$ of $3.2 \mathrm{kA} / \mathrm{m}$ was obtained at $\mathrm{Ni}-20 \mathrm{~mol} \% \mathrm{Fe}$ seed layer of $3 \mathrm{~nm}$. The increase of $H_{\mathrm{ex}}$ and $H_{\mathrm{c}}$ seems to be attributed by a change of the crystalline of $\mathrm{Mn}-17 \mathrm{~mol} \% \mathrm{Ir}-2 \mathrm{~mol} \% \mathrm{Pt}$ by variation of $\mathrm{Ni}-20 \mathrm{~mol} \% \mathrm{Fe}$ seed layer.

For a SVs with $\gamma$-phase AFM, The (111) texture of AFM have been known to improve $H_{\mathrm{ex}}$ at the interface between AFM and FM layers. As shown in Fig. 2, the (111) peaks of $\mathrm{Mn}-17 \mathrm{~mol} \% \mathrm{Ir}-2 \mathrm{~mol} \% \mathrm{Pt}$ and $\mathrm{Ni}-20 \mathrm{~mol} \% \mathrm{Fe}$ become stronger with increasing a $\mathrm{Ni}-20 \mathrm{~mol} \% \mathrm{Fe}$ seed thick- 


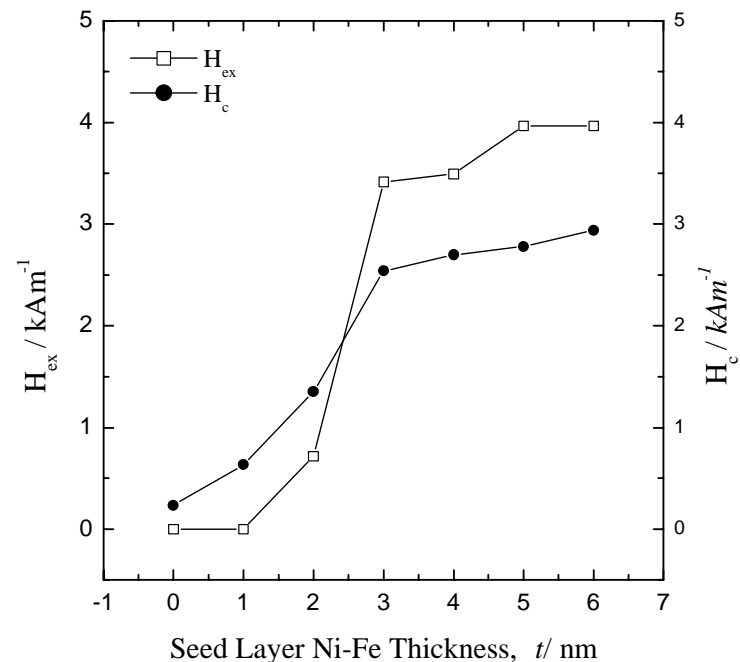

Fig. 1 Variations of $H_{\mathrm{ex}}$ and $H_{\mathrm{c}}$ of $\mathrm{Si} / \mathrm{Ta} \quad 3 \mathrm{~nm} / \mathrm{Ni}-20 \mathrm{~mol} \% \mathrm{Fe} \quad \mathrm{t}$ $\mathrm{nm} / \mathrm{Mn}-17 \mathrm{~mol} \% \mathrm{Ir}-2 \mathrm{~mol} \% \mathrm{Pt} 10 \mathrm{~nm} / \mathrm{Ni}-20 \mathrm{~mol} \% \mathrm{Fe} 10 \mathrm{~nm}$.

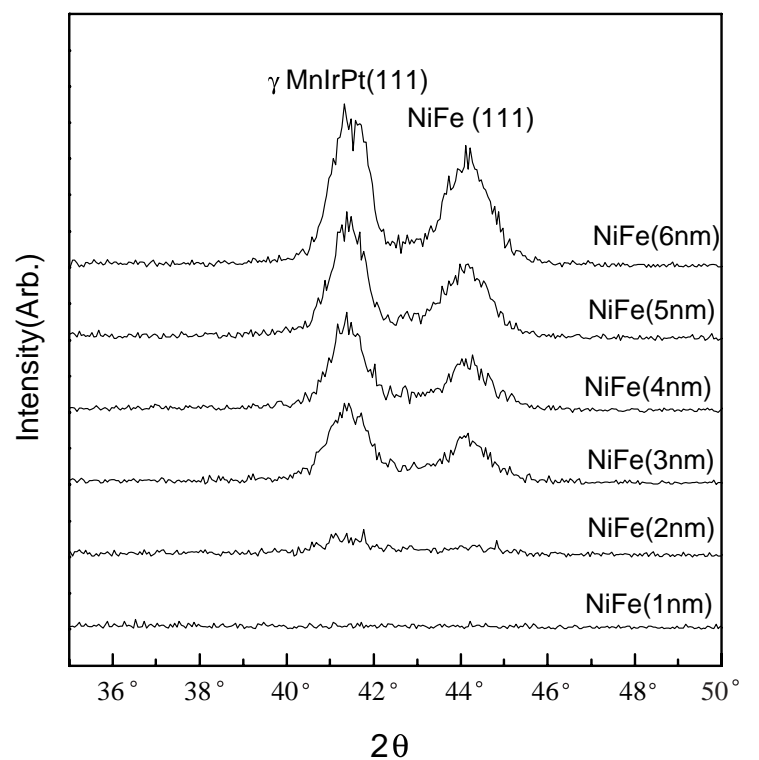

Fig. 2 X-ray diffraction patterns of Ta $3 \mathrm{~nm} / \mathrm{Ni}-20 \mathrm{~mol} \% \mathrm{Fe} \mathrm{t} \mathrm{nm} / \mathrm{Mn}-$ $17 \mathrm{~mol} \% \mathrm{Ir}-2 \mathrm{~mol} \% \mathrm{Pt} 10 \mathrm{~nm} / \mathrm{Ta} 5 \mathrm{~nm}$ as a function of a seed layer (Ni-20 mol\%Fe) thickness.

ness.

The thicker $\mathrm{Ni}-20 \mathrm{~mol} \% \mathrm{Fe}$ could be expected to better promote (111) texture of the Mn-17 mol\% Ir-2 mol\%Pt layer. The Ni-20 mol\%Fe seed thickness of over $3 \mathrm{~nm}$ was considered to render a large $H_{\mathrm{ex}}$ to a bottom SV film. We also confirmed the developed the (111) texture of Mn-17 mol\% Ir2 mol\%Pt AFM layer by using a High resolution TEM.

Figure 3 shows the dependence of $H_{\mathrm{ex}}$ on $\mathrm{Mn}-$ $17 \mathrm{~mol} \% \mathrm{Ir}-2 \mathrm{~mol} \% \mathrm{Pt}$ thickness for bottom SVs composed of $\mathrm{Ta} / \mathrm{Ni}-20 \mathrm{~mol} \% \mathrm{Fe} 3 \mathrm{~nm} / \mathrm{Mn}-17 \mathrm{~mol} \% \mathrm{Ir}-2 \mathrm{~mol} \% \mathrm{Pt} \mathrm{t} \mathrm{nm} / \mathrm{Co}-$ $10 \mathrm{~mol} \% \mathrm{Fe} 2 \mathrm{~nm} / \mathrm{Ta} 5 \mathrm{~nm}$. The high $H_{\text {ex }}$ of $17.4 \mathrm{kA} / \mathrm{m}$ was obtained at Mn-17 mol\% Ir-2 mol\%Pt thickness of $6 \mathrm{~nm}$. And the SVs with thicker Mn-17 mol\%Ir-2 mol\%Pt show a steep decrease of the $H_{\mathrm{ex}}$. In case of a top SV, the decrease of $H_{\mathrm{ex}}$ is not steep like a bottom SV. It may be thought that the number of AFM grains strongly blocking the spin reversal of FM in a bottom SV is smaller than that of top SV. ${ }^{6}$ ) However, we

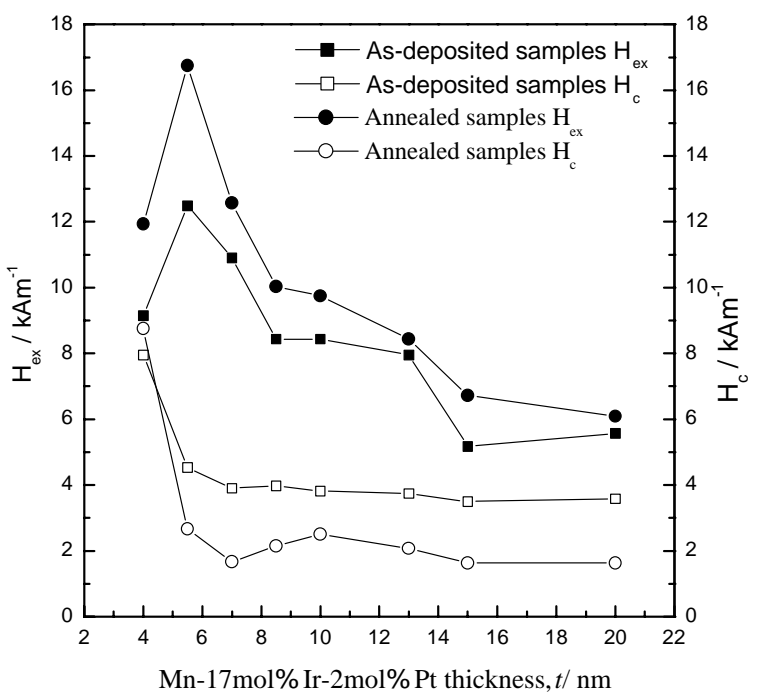

Fig. 3 Variation of Magnetic properties as a function of $\mathrm{Mn}-17 \mathrm{~mol} \% \mathrm{Ir}-$ $2 \mathrm{~mol} \% \mathrm{Pt}$ thickness. The film structure used is Ta $3 \mathrm{~nm} / \mathrm{NiFe}$ $3 \mathrm{~nm} / \mathrm{Mn}-17 \mathrm{~mol} \% \mathrm{Ir}-2 \mathrm{~mol} \% \mathrm{Pt} \mathrm{t} \mathrm{nm} / \mathrm{Co}-10 \mathrm{~mol} \% \mathrm{Fe} 1 \mathrm{~nm} / \mathrm{Ta} 3 \mathrm{~nm}$.

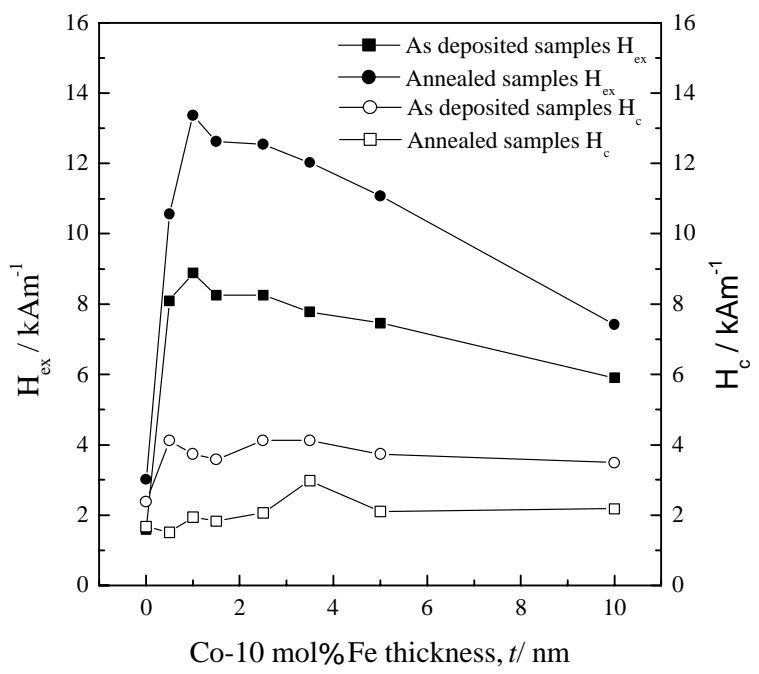

Fig. 4 Variation of $H_{\mathrm{c}}$ and $H_{\mathrm{ex}}$ as a function of Co-10 mol\%Fe thickness in $\mathrm{Si} / \mathrm{Ni}-20 \mathrm{~mol} \% \mathrm{Fe} 3 \mathrm{~nm} / \mathrm{Mn}-17 \mathrm{~mol} \% \mathrm{Ir}-2 \mathrm{~mol} \% \mathrm{Pt} 6 \mathrm{~nm} / \mathrm{Co}-10 \mathrm{~mol} \% \mathrm{Fe} \mathrm{t}$ $\mathrm{nm} / \mathrm{Ni}-20 \mathrm{~mol} \% \mathrm{Fe} 10 \mathrm{t} \mathrm{nm} / \mathrm{Ta}$ multilayers.

failed to characterize the effect of grain size on the $H_{\mathrm{ex}}$ in a bottom SVs by using various analyzing tools.

We tried to improve the $H_{\mathrm{ex}}$ of bottom SVs by inserting the $\mathrm{Co}-10 \mathrm{~mol} \% \mathrm{Fe}$ layer into the $\mathrm{Mn}-17 \mathrm{~mol} \% \mathrm{Ir}-$ $2 \mathrm{~mol} \% \mathrm{Pt}$ and $\mathrm{Ni}-20 \mathrm{~mol} \% \mathrm{Fe}$ layer. Figure 4 shows the variation of the $H_{\mathrm{ex}}$ and $H_{\mathrm{c}}$ in typical structure of $\mathrm{Si} / \mathrm{Ta} 3 \mathrm{~nm} / \mathrm{Ni}-20 \mathrm{~mol} \% \mathrm{Fe} 3 \mathrm{~nm} / \mathrm{Mn}-17 \mathrm{~mol} \% \mathrm{Ir}-$ $2 \mathrm{~mol} \% \mathrm{Pt} \quad 6 \mathrm{~nm} / \mathrm{Co}-10 \mathrm{~mol} \% \mathrm{Fe} \quad(\mathrm{t}) \mathrm{nm} / \mathrm{Ni}-20 \mathrm{~mol} \% \mathrm{Fe} \quad(10-$ t) nm/Ta $3 \mathrm{~nm}$ multilayers. After annealing at $453 \mathrm{~K}$ for $1 \mathrm{~h}$, the $H_{\mathrm{ex}}$ of $13.5 \mathrm{kA} / \mathrm{m}$ could be obtained in Bottom SV including $1 \mathrm{~nm}$ thick $\mathrm{Co}-10 \mathrm{~mol} \% \mathrm{Fe}$ layer. The high magnetization value of $\mathrm{Co}-10 \mathrm{~mol} \% \mathrm{Fe}$ can be thought to give a high anisotropy to a bottom SV. The high $H_{\mathrm{ex}}$ of a bottom SV shows that Mn-17 mol\% Ir-2 mol\%Pt can be a candidate for a dual or a symmetric valve.

We prepared a top SV composing of Ta $3 \mathrm{~nm} / \mathrm{Ni}-$ $20 \mathrm{~mol} \% \mathrm{Fe} \quad 6 \mathrm{~nm} / \mathrm{Co}-10 \mathrm{~mol} \% \mathrm{Fe} \quad 1.5 \mathrm{~nm} / \mathrm{Cu} \quad 2.5 \mathrm{~nm} / \mathrm{Co}-$ $10 \mathrm{~mol} \% \mathrm{Fe} \quad 1.5 \mathrm{~nm} / \mathrm{Ni}-20 \mathrm{~mol} \% \mathrm{Fe} \quad 3.5 \mathrm{~nm} / \mathrm{Co}-10 \mathrm{~mol} \% \mathrm{Fe}$ 

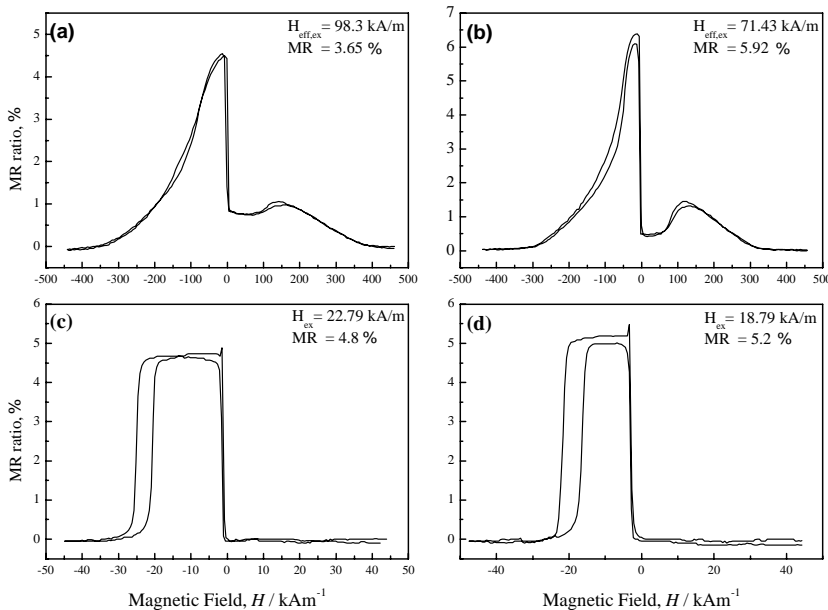

Fig. 5 MR curves of (a) a synthetic top SV, (b) synthetic bottom SV, (c) top SV and (d) bottom SV.

$1 \mathrm{~nm} / \mathrm{Mn}-\mathrm{Ir}-\mathrm{Pt} 10 \mathrm{~nm} / \mathrm{Ta} 1.5 \mathrm{~nm}$ and a bottom SV composing of Ta $3 \mathrm{~nm} / \mathrm{Ni}-20 \mathrm{~mol} \% \mathrm{Fe} 3 \mathrm{~nm} / \mathrm{Mn}-17 \mathrm{~mol} \% \mathrm{Ir}-2 \mathrm{~mol} \% \mathrm{Pt}$ $7 \mathrm{~nm} / \mathrm{CoFe} \quad 1 \mathrm{~nm} / \mathrm{Ni}-20 \mathrm{~mol} \% \mathrm{Fe} \quad 5 \mathrm{~nm} / \mathrm{Cu} \quad 2.5 \mathrm{~nm} / \mathrm{Co}-$ $10 \mathrm{~mol} \% \mathrm{Fe} 1.5 \mathrm{~nm} / \mathrm{Ni}-20 \mathrm{~mol} \% \mathrm{Fe} 6 \mathrm{~nm} / \mathrm{Ta} 1.5 \mathrm{~nm}$. A top SV film shows a high $H_{\mathrm{ex}}$ of about $22.7 \mathrm{kA} / \mathrm{m}$ and GMR ratio of about $4.8 \%$. A bottom SV shows a high $H_{\mathrm{ex}}$ of about $18.8 \mathrm{kA} / \mathrm{m}$ and GMR ratio of about $5.2 \%$ comparable with a top SV. Because the free layer of a bottom SV is located at near of surface, the spin dependent scattering mainly occurs in free layer. For a bottom SV, the dependence of GMR on free layer thickness is much larger than the a top SV. ${ }^{7)}$

The GMR devices with sub-micron size require the stable spin rotation and the better thermal stability. Thus, in order to obtain an enhanced thermal stability of $H_{\mathrm{ex}}$ and GMR we applied a synthetic antiferromagnetically coupled pinned layer to a bottom SV. We deposited a synthetic antiferromagnet $(\mathrm{Co}-10 \mathrm{~mol} \% \mathrm{Fe}, \mathrm{P} 130 \mathrm{~nm} / \mathrm{Ru} 8 \mathrm{~nm} / \mathrm{Co}-10 \mathrm{~mol} \% \mathrm{Fe}, \mathrm{P} 2$ $30 \mathrm{~nm}$ ) between $\mathrm{Mn}-17 \mathrm{~mol} \% \mathrm{Ir}-2 \mathrm{~mol} \% \mathrm{Pt}$ and $\mathrm{Cu}$ layers of bottom SVs. ${ }^{8)}$ The spin rotation of a pinned layer is controlled by the magnetization reversal of P1 (adjacent with $\mathrm{Mn}-17$ mol\% Ir-2 mol\% Pt) and P2 (adjacent with $\mathrm{Cu}$ ). The strong AFM coupling of P1 and P2 contributes to the large $H_{\text {ex }}$, which is called the effective exchange field $\left(H_{\text {eff,ex }}\right)$ in a synthetic SV. The $H_{\text {eff,ex }}$ is defined as a external field at a half of maximum GMR. Figure 5 shows the MR curves of various SVs. A synthetic top $\mathrm{SV}$ is composed of $\mathrm{Ta}$ $3 \mathrm{~nm} / \mathrm{Ni}-20 \mathrm{~mol} \% \mathrm{Fe} 6 \mathrm{~nm} / \mathrm{Co}-10 \mathrm{~mol} \% \mathrm{Fe} 1.5 \mathrm{~nm} / \mathrm{Cu} 2.5 \mathrm{~nm} /$ $\mathrm{Co}-10 \mathrm{~mol} \% \mathrm{Fe} 3 \mathrm{~nm} / \mathrm{Ru} \quad 0.8 \mathrm{~nm} / \mathrm{Co}-10 \mathrm{~mol} \% \mathrm{Fe} 3 \mathrm{~nm} / \mathrm{Mn}-$ $17 \mathrm{~mol} \% \mathrm{Ir}-2 \mathrm{~mol} \% \mathrm{Pt} 10 \mathrm{~nm} / \mathrm{Ta} 1.5 \mathrm{~nm}$. A synthetic bottom $\mathrm{SV}$ is composed of Ta $3 \mathrm{~nm} / \mathrm{Ni}-20 \mathrm{~mol} \% \mathrm{Fe} 3 \mathrm{~nm} / \mathrm{Mn}-$ $17 \mathrm{~mol} \% \mathrm{Ir}-2 \mathrm{~mol} \% \mathrm{Pt} 7 \mathrm{~nm} / \mathrm{Co}-10 \mathrm{~mol} \% \mathrm{Fe} 3 \mathrm{~nm} / \mathrm{Ru} 0.8 \mathrm{~nm} /$ $\mathrm{Co}-10 \mathrm{~mol} \% \mathrm{Fe} 3 \mathrm{~nm} / \mathrm{Cu} 2.5 \mathrm{~nm} / \mathrm{Co}-10 \mathrm{~mol} \% \mathrm{Fe} 1.5 \mathrm{~nm} / \mathrm{Ni}-$ $20 \mathrm{~mol} \% \mathrm{Fe} 6 \mathrm{~nm} / \mathrm{Ta} 1.5 \mathrm{~nm}$. The $H_{\text {eff,ex }}$ of both synthetic SVs exhibits higher than a conventional SVs. A synthetic top SV shows the $H_{\text {eff,ex }}$ of $98.26 \mathrm{kA} / \mathrm{m}$. A synthetic bottom SV exhibits the $H_{\text {eff,ex }}$ of $71.43 \mathrm{kA} / \mathrm{m}$. The synthetic top SVs show a decrease of GMR by a shunt effect due to a thicker pinned layer. ${ }^{9,10)}$ But, for a synthetic bottom SV a GMR is roughly constant. It represents that a spin dependent scattering largely comes from a free layer. We found that a synthetic bottom SV did not depends strongly on the thickness of pinned layer

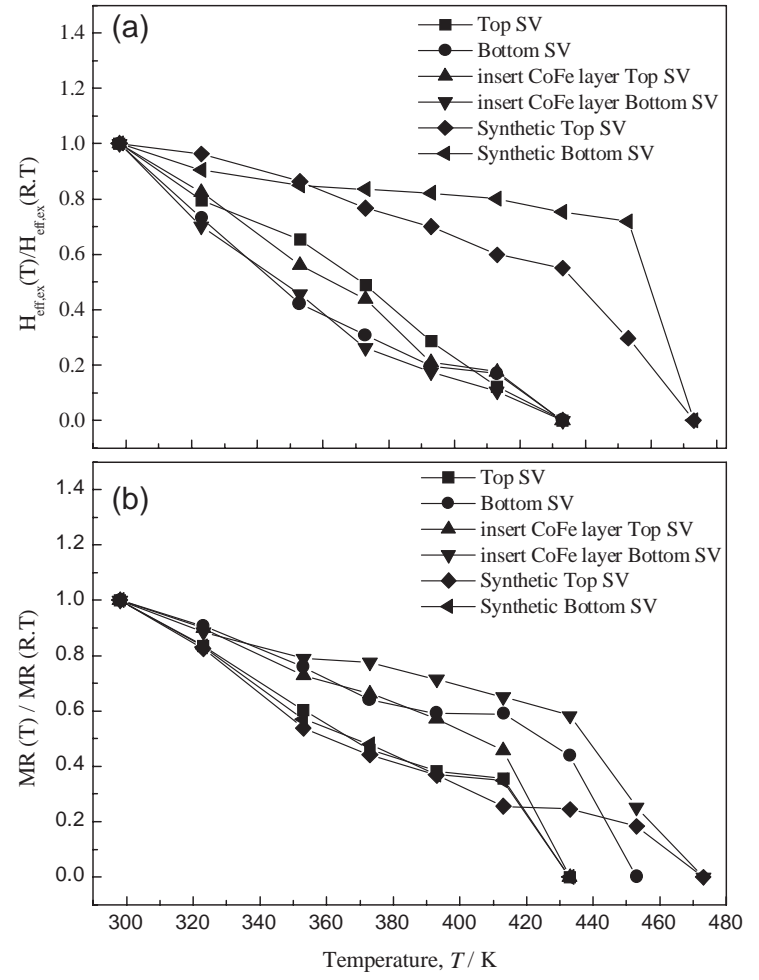

Fig. 6 Temperature dependence of (a) $H_{\mathrm{ex}}$, (b) GMR of various SVs. The $\mathrm{Co}-10 \mathrm{~mol} \% \mathrm{Fe}$ layer of $1 \mathrm{~nm}$ was inserted between $\mathrm{Ni}-20 \mathrm{~mol} \% \mathrm{Fe}$ and Mn-17 mol\% Ir-2 mol\%Pt layers.

but when the one of P1 and P2 layers is much thinner than the mean free path of spin a bottom SV shows a low GMR ratio. ${ }^{11)}$

We evaluated the thermal stability of a $H_{\mathrm{ex}}$, a $H_{\mathrm{eff}, \mathrm{ex}}$ and a GMR in various SVs. As shown in Fig. 6, synthetic SVs exhibit an excellent thermal stability of $H_{\mathrm{ex}}$ due to a strong antiferromagnetic coupling of pinned layers. However, It is interesting that the thermal properties of GMR in a synthetic bottom SV is similar to that of a conventional SV. The intermixing of $\mathrm{Co}-10 \mathrm{~mol} \% \mathrm{Fe} / \mathrm{Ru} / \mathrm{Co}-10 \mathrm{~mol} \% \mathrm{Fe}$ layers may cause the rapid decrease of GMR in a synthetic top $\mathrm{SVs}$. It needs a further study on the intermixed layer of $\mathrm{Co}-$ $10 \mathrm{~mol} \% \mathrm{Fe} / \mathrm{Ru} / \mathrm{Co}-10 \mathrm{~mol} \% \mathrm{Fe}$.

\section{Conclusions}

In summary, we fabricated a various SVs composing of Mn-17 mol\%Ir-2 mol\%Pt AFM layer. The high $H_{\text {ex }}$ of a bottom SV film can be improved by the promotion of a (111) texture in Mn-17 mol\%Ir-2 mol\%Pt layer. A high $H_{\text {eff,ex }}$ could be obtained in synthetic top and bottom SVs. For a synthetic bottom SV, the thermal stability of GMR was superior to a synthetic top SV. It is thought that the intermixed interface of $\mathrm{Co}-10 \mathrm{~mol} \% \mathrm{Fe} / \mathrm{Ru} / \mathrm{Co}-10 \mathrm{~mol} \% \mathrm{Fe}$ layer should cause a poor thermal stability of GMR at a high temperature.

\section{Acknowledgments}

We gratefully acknowledge the financial support from the Korea Research Foundation (KRF-99-042-E00106 E5105). 


\section{REFERENCES}

1) R. Nakatani, H. Hoshiya, K. Hoshino and Y. Sugita: J. Magn. Magn. Mater. 173 (1997) 321-330.

2) T. Lin, D. Mauri, N. Staud, C. Hwang, J. K. Howard and G. L. Gorman: Appl. Phys. Lett. 65 (1994) 2585-2588.

3) J. C. Ro, Y. K. Kim, S. Y. Yoon, J. H. Park, D. M. Jeon and S. J. Suh: IEEE Trans. Magn. 36 (2000) 2569-2571.

4) T. Shimizu, H. Kishi, K. Nagasaka, H. Kanai and M. Oshiki: IEEE Trans. Magn. 35 (1999) 700-702.

5) K. Nishioka, S. Shigematsu, T. Imagqwa and S. Narishige: J. Appl. Phys. 83 (1998) 3233-3238.
6) C. Binek, A. Hochstrat and W. Kleemann: J. Magn. Magn. Mater. 234 (2001) 353-358.

7) P. M. Levy: Solid State Phys. 47 (1994) 367-462.

8) Y. Huai, J. Zhang, G. W. Anderson, P. Rana, S. Funada, C. Y. Hung, M. Zhao and S. Tran: J. Appl. Phys. 85 (1999) 5528-5530.

9) B. Dieny, M. Li, H. Liao, C. Hong and K. Ju: J. Appl. Phys. 87 (2000) 3415-3420.

10) J. Chen, S. Mao, J. F. Castro, T. S. Choy and S. Hershfield: IEEE Trans. Magn. 36 (2000) 2885-2887.

11) D. M. Jeon, J. H. Kim, Y. S. Kim. D. H. Lee, D. H. Yoon and S. J. Suh: J. Magn. Magn. Mater. (2001) in press. 